\title{
MOVIMENTOS SOCIAIS, PARTICIPAÇÃO E INCIDÊNCIA NAS POLÍTICAS PÚBLICAS LOCAIS
}

\author{
SOCIAL MOVEMENTS, PARTICIPATION AND \\ IMPACT ON LOCAL PUBLIC POLICIES
}

\author{
Orlandil de Lima Moreira ${ }^{1}$ \\ Idalina Maria Freitas Lima Santiago ${ }^{2}$
}

\section{RESUMO}

A presença dos movimentos sociais no cenário político brasileiro faz parte de sua história política, com participação em diferentes momentos históricos, tendo como um dos seus eixos de atuação a luta pela democratização do Estado e da sociedade. Nos períodos de autoritarismo vividos no Brasil, os movimentos sociais resistiram aos regimes ditatoriais, com destaque para o período mais recente de ditadura civil militar de 1964 a 1985. Nesse período, foram interrompidas a participação social e ampliação da democracia. Mesmo sob o regime autoritário, os anos de 1980 foram marcados pela ampliação das mobilizações sociais, destacando-se como a "década da participação". A promulgação da Constituição em 1988 representou uma conquista para o fortalecimento da democracia e dos direitos sociais. Nesse contexto a participação os espaços públicos institucionais foram se ampliando, e fortalecendo a constituição de uma esfera pública, até então fragilizada. $\mathrm{O}$ artigo tem como objetivo problematizar a incidência dos movimentos sociais nas políticas públicas no âmbito local, destacando os avanços e conquistas frente ao conservadorismo do poder local para a participação cidadã na elaboração das políticas públicas. A presença dos movimentos sociais teve papel importante nesse processo como atores coletivos relevantes para as mudanças políticas acontecidas no Brasil. Trata-se de um movimento de renovação da cultura política que tem contribuído para a efetivação da democracia participativa como assegura a Constituição de 1988 .

Palavras-chave: Movimentos Sociais; Políticas Públicas; Cidadania.

\begin{abstract}
The presence of social movements in the Brazilian political scene is part of its political history, with participation in different historical moments, having as one of its axes of action the struggle for the democratization of the State and society. During the periods of authoritarianism experienced in Brazil, social movements resisted dictatorial regimes, most notably the most recent period of civilian military dictatorship from 1964 to 1985. During this period, social participation and the expansion of democracy were interrupted. Even under the authoritarian regime, the 1980s were marked by the expansion of social mobilizations, standing out as the "decade of participation". The enactment of the Constitution in 1988 represented an achievement for the strengthening of democracy and social rights. In this context, the participation of institutional public spaces was broadening, and strengthening the constitution of a public sphere, hitherto weakened. The article aims to problematize the impact of social movements on public policies at the local level, highlighting the advances and achievements against the conservatism of local power for citizen participation in the elaboration of public policies. The presence of social movements played an important role in this process as collective actors relevant
\end{abstract}

\footnotetext{
1 Doutor em Ciências Sociais pela PUC/SP, Professor do Departamento de Metodologia da Educação da Universidade Federal da Paraíba (UFPB) e líder do grupo de pesquisa observatório da Educação Popular. E-mail: orlandil@hotmail.com.

${ }^{2}$ Doutora em Ciências Sociais pela PUC/SP, professora do Programa de Pós-graduação em Serviço Social e da graduação da Universidade Estadual da Paraíba (UEPB) e Líder do grupo de pesquisa Flor e Flor: estudos de gênero. E-mail: imfls@uol.com.br.
}

Revista Debates Insubmissos, Caruaru, PE. Brasil, v.1, n.1, jan./abr. 2018. Endereço: https://periodicos.ufpe.br/revistas/debatesinsubmissos/ 
to the political changes in Brazil. It is a movement of renewal of the political culture that has contributed for the realization of the participatory democracy as it secures the Constitution of 1988.

Keywords: Social Movements. Public Policy. Citizenship.

\section{INTRODUÇÃO}

A presença dos movimentos sociais no cenário político brasileiro faz parte de sua história política, com participação em diferentes momentos históricos e conjunturais, tendo como um dos seus eixos de atuação a luta pela democratização do Estado e da sociedade. Nos períodos de autoritarismo vivenciados ao longo de nossa história política, os movimentos sociais resistiram e sofreram as consequências dos regimes ditatoriais, com destaque para o período mais recente de ditadura civil militar de 1964 a 1985. Fase de nossa história política em que os movimentos sociais foram atacados pelo regime de exceção, suas lideranças torturadas e muitas assassinadas por um regime marcado pelo autoritarismo e violência de Estado. As cicatrizes políticas ainda estão abertas, muitas das atrocidades e mortes ocorridas com lideranças de movimentos sociais ainda estão impunes. A reconstrução dessa memória é fundamental para a consolidação da democracia.

O Estado brasileiro nesse período interrompeu os processos de participação social e ampliação da democracia que vinham se construindo, com forte presença dos movimentos sociais das cidades e do campo, a exemplo das ligas camponesas na região Nordeste, movimento camponês que tinha como principal bandeira a luta pela reforma agrária. Nesse contexto de autoritarismo, os movimentos e organizações populares que desenvolviam ações em defesa de uma sociedade democrática e com justiça social foram desmantelados, restandolhes apenas a clandestinidade para continuarem na sua luta.

Nos anos de 1970, nos anos mais difíceis da ditadura militar os movimentos sociais, mesmo à margem do cenário político, pela força da repressão, retomaram suas ações nas periferias urbanas e comunidades rurais, tendo a Educação Popular e a Teologia da Libertação como instrumentais metodológicos e educativos para contribuir com o retorno das ações políticas. Atividades sociais, políticas e educativas foram desenvolvidas nessa década 
possibilitando a volta das mobilizações políticas e fazendo surgir nesse contexto o novo sindicalismo e os movimentos populares; ambos com suas ações mudaram o cenário político brasileiro e se constituíram como atores importantes para o processo de democratização da sociedade brasileira (SADER, 1988).

Nesse período, quando a ditadura militar já apresenta suas debilidades, entrando num momento denominado de "distensão política", começa a se construir um novo contexto político, "quando novos personagens entraram em cena", como afirma Sader (1988), diversificando assim os atores políticos coletivos e individuais no cenário político. A sociedade brasileira já não aceitava passivamente o regime ditatorial, intensificando-se as mobilizações sociais e políticas, envolvendo diversos segmentos sociais.

O Estado brasileiro com seu padrão autoritário e intervencionista, característica relevante da ditadura civil militar, não apresentava nenhuma preocupação com a construção de instituições democráticas que possibilitassem à população o acesso aos espaços de decisão, com participação popular. Ao contrário, interrompeu qualquer processo de participação política e se pautou no clientelismo.

Mesmo sob o regime autoritário até o ano de 1985, essa década foi marcada pela ampliação das mobilizações sociais e políticas, destacando-se como a "década da participação". Momento histórico importante para a participação popular, tendo como marcos políticos importantes a luta pelas eleições diretas, com o movimento das "Diretas Já" e a mobilização para a realização de uma Constituinte. A presença dos movimentos sociais nesse período foi relevante para a ampliação da democracia, com o fim do regime militar e, em seguida, a conquista de mecanismos que ampliaram a participação direta e a democracia participativa na nova Constituição.

Mesmo diante de um cenário mundial com forte presença no pensamento neoliberal, influenciando fortemente as ações políticas no mundo, a promulgação da Constituição, em 1988, representou para a sociedade brasileira uma conquista para a construção e fortalecimento da democracia e dos direitos sociais. Nesse novo contexto político, os processos de participação e os espaços públicos institucionais foram se ampliando, constituindo-se uma esfera pública, até então fragilizada. 
Importa neste artigo não destacar as derrotas, mas evidenciar as mudanças que foram possibilitadas e conquistadas pelas ações dos movimentos sociais, com a democratização da sociedade brasileira no campo das políticas públicas. A nossa opção por evidenciar as conquistas é porque, dessa forma, entendemos que podemos recuperar os ânimos para continuamos lutando, principalmente neste momento de clara onda conservadora, em que não se avançou em nada no Brasil e muitos querem o retorno de momentos autoritários. Como afirma Santomé (2013, p. 223): “Reconhecer os avanços, além de manifestar algo objetivo, ajuda a insuflar mais os ânimos entre aqueles que se unem a essa lutas e incentiva as formas de analisar e avaliar o sucesso e os obstáculos presentes no caminho”.

O presente artigo tem como objetivo problematizar a incidência dos movimentos sociais nas políticas públicas no âmbito local, nos últimos anos, destacando nesse processo os avanços e conquistas dos movimentos sociais frente ao conservadorismo do poder local para a participação dos cidadãos na elaboração e controle social das políticas públicas.

O estudo tem como campo de investigação a ação política desenvolvida pelos movimentos sociais populares na região do brejo paraibano, no município de Guarabira. Território em que desenvolvo pesquisas e extensão em parceria com o SEDUP Serviço de Educação Popular, organização não governamental que tem atuação na região. $O$ presente estudo é resultado de observação participante junto ao Fórum de Organização e Movimentos Sociais de Guarabira na incidência política no poder local, para o controle social do processo de elaboração do orçamento público. Análise que foi referenciada por estudo bibliográfico acerca do tema em estudo.

\section{OS ANOS DE 1980: A DÉCADA DA PARTICIPAÇÃO}

Nos anos de 1980, o Brasil assiste a mudanças políticas relevantes para a democracia brasileira. Ainda sob o domínio da ditadura civil militar, os movimentos sociais intensificam o seu processo de organização e mobilização social, evidenciando na cena pública as condições de vida das parcelas empobrecidas da sociedade. Através de sua organização denunciaram as condições de exploração no trabalho, as carências e contradições urbanas, a situação de exploração no campo e a falta de acesso à terra para os camponeses. As 
organizações e movimentos sociais que resistiram na clandestinidade das periferias das cidades vão às ruas e conquistam visibilidade política. $\mathrm{O}$ apoio da Igreja Católica através da Teologia da Libertação com sua ação nas comunidades eclesiais de base destaca-se como uma participação relevante nesse processo (KRISCHKE; MAINWARING, 1986).

Nesse contexto sociopolítico, eclodem mobilizações de trabalhadores do campo e da cidade em todo Brasil, com destaque para as greves dos metalúrgicos no ABC paulista, mas que se estendeu também para outros centros industriais; assim como as greves de trabalhadores assalariados rurais, em especial os canavieiros das indústrias sucroalcooleiras das regiões Nordeste e Sudeste brasileiro. Nas periferias urbanas emergem os movimentos sociais populares, denominados pela literatura política de "movimentos populares", os quais trazem para o cenário político reivindicações por direitos, questionando o seu lugar à margem da cidadania. Nesse processo, constituíram-se enquanto atores políticos, denunciando a falta de acesso às políticas públicas e reivindicando o "direito a ter direitos".

Assistem-se nesse momento, no Brasil, ao fortalecimento da participação social e política dos vários segmentos sociais, tendo como foco os direitos da cidadania relativos às políticas públicas. Nesse tempo, emergem várias organizações e movimentos populares, trazendo para a pauta política questões específicas que atingem os segmentos sociais empobrecidos, a exemplo dos moradores das periferias urbanas, donas de casa, negros, juventudes, trabalhadores rurais etc. Movimentos que vão se juntar aos demais setores progressistas e partidos políticos nas mobilizações pelas "Diretas Já" e pela elaboração de uma Constituição, após o fim da ditadura militar em 1985.

Os processos de mobilização social que vinham se constituindo desde os anos de 1970 foram fundamentais nesse momento, a capacidade e força social que foram se acumulando nesse tempo fez a diferença para a participação popular no processo constituinte. Através das várias ações pressionaram os deputados constituintes para incluíram as demandas da sociedade na nova Constituição. Vários abaixo-assinados foram realizados junto à população e enviados ao Congresso Constituinte apresentados através de emendas populares. Uma emenda que se destacou entre as muitas enviadas foi a que tratava de inserir na Constituição 
instrumentos e formas de participação popular. Como indica estudo realizado sobre esse processo político,

De fato, esta emenda, diferente de todas as demais apresentadas, não traduzia um anseio de um setor específico da sociedade nem procurava a uma necessidade material de vida. Ela se voltava para o próprio funcionamento do processo democrático, para as condições mesmas de exercício da cidadania” (MICHILES et al., 1989, p. 92-93).

Esse processo de intensa mobilização social resultou na promulgação de uma Constituição que apresentou avanços importantes no campo social e político, o que lhes conferiu a denominação de "Constituição Cidadã".

Essa ideia de incluir na nova Constituição novos instrumentos participativos, como afirma o estudo "já era ponto pacífico entre os que se mobilizavam para isso" (MICHILES et al., 1989, p. 93). As conquistas resultantes das ações das organizações e movimentos sociais incorporadas na nova Carta Magna colocam para estes atores desafios no campo da participação, agora com possibilidades concretas de participar dos espaços institucionais de gestão das políticas públicas, agora compartilhados com representantes do Estado.

Nesse cenário participacionista, com forte presença dos movimentos sociais assiste-se ao fortalecimento da sociedade civil, até então fragilizada. A partir desse quadro político, coloca-se a necessidade de "refundar a legitimidade do Estado", por meio da participação da sociedade civil em suas instâncias decisórias e no controle social das políticas públicas. Como afirma Moreira (2011, p. 361), “é nesse sentido que a participação dos cidadãos na gestão pública ganha significado, e passa a ser incorporada nos novos formatos de participação no âmbito local".

A presença das organizações e movimentos sociais nos espaços que vão se constituindo no âmbito local passa a ser pauta política desses sujeitos coletivos, ocupando grande parte do tempo nos momentos de planejamento de suas ações e formação política, tendo em vista ser esta uma nova demanda no campo da participação.

Nesse sentido, as iniciativas de organização de fóruns populares para a participação cidadã no âmbito local se constitui em uma ação política importante, podendo ser observada 
em diversas regiões e cidades do Brasil, principalmente, naquelas cidades onde o grau de organização da sociedade civil está mais consolidado (BALCÃO; TEIXEIRA, 2003), ação que vai ganhar maior capacidade de expansão nos anos de 1990.

\section{PARTICIPAÇÃO POPULAR E INCIDÊNCIA NAS POLÍTICAS PÚBLICAS}

Com a promulgação da nova Constituição em outubro de 1988, a democracia brasileira já não se caracteriza apenas como um sistema de democracia representativa, passa a ser assegurado também mecanismos de participação direta e semidireta, ampliando-se os processos participativos, na direção da democracia participativa, como previsto no parágrafo único do artigo $1^{\circ}$ da Constituição: "Todo poder emana do povo, que o exerce por meio de representantes eleitos ou diretamente, nos termos desta Constituição” (BRASIL, 2002).

A partir dos anos de 1990, do ponto de vista institucional estão criadas as condições para a ampliação da participação cidadã na esfera pública, alterando a ideia da privatização do Estado e mudanças da relação Estado e sociedade. Movimentos associativos vão se constituindo no sentido de provocar o aumento da participação da sociedade civil nas decisões estatais, na perspectiva de redefinir o poder exclusivo das elites de definir políticas e implementar ações públicas, como sugere análise do grupo de estudos sobre a construção democrática da UNICAMP:

\footnotetext{
No contexto destas experiências, que se desenvolveram no fim dos anos 80 , a expectativa era a de promover a abertura do Estado para aqueles diferentes setores, que tinham em comum o fato de se constituírem como os historicamente excluídos dos direitos sociais (GRUPO DE ESTUDO SOBRE CONSTRUÇÃO DEMOCRÁTICA, 1998/99, p. 79).
}

A democracia participativa sempre esteve presente nos ideários dos movimentos sociais, sendo possível a sua concretização só agora com a promulgação da Constituição de 1988, quando vários instrumentos e mecanismos de participação foram aprovados, com destaque para os artigos que possibilitaram a gestão participativa das políticas públicas (Educação, Saúde, Assistência Social etc.), complementados pelas leis orgânicas relativas a cada política social. 
O momento seguinte foi de esforço para a efetivação de tais mecanismos, e assim construir um novo patamar de participação popular no Brasil, onde o diálogo entre sociedade civil e governo passa a ter uma centralidade, através da construção de espaços públicos institucionais. A análise das autoras Almeida e Tatagiba sobre esse momento político nos ajuda a pensar como esse debate vem se colocando no Brasil.

O pressuposto central nesse debate, ainda que abrigue divergências e ênfases analíticas variadas, é o de que a legitimidade democrática nas sociedades contemporâneas, nas quais vigoram amplos dissensos e/ou fortes desigualdades, não pode ser satisfeita restritamente pela técnica de decisão aritmética das urnas (ALMEIDA; TATAGIBA, 2012, p. 70).

O contexto político que se desenha a partir de tais mudanças possibilitou a construção de espaços públicos com o objetivo de serem órgãos propositivos e de controle social das políticas públicas, tendo os conselhos gestores como um dos principais mecanismos para este fim, os quais são instâncias que se particularizam no interior do sistema decisório das políticas públicas pelo seu caráter plural e híbrido, por ser compostos por representantes da sociedade civil e do Estado (MOREIRA, 2002).

No âmbito local, a participação no planejamento municipal também foi assegurada pelo inciso XII do parágrafo 29 da Constituição, ao definir que deve haver "cooperação das associações representativas no planejamento municipal”. Nesse contexto de ampliação da participação nos processos decisórios e espaços de planejamento das políticas públicas, vão se constituindo diversos arranjos políticos, tendo como referência as normatividades constitucionais, formatando na sociedade civil um novo desenho participativo.

No âmbito da sociedade civil também vão emergir novos arranjos organizativos no sentido de incidirem nos espaços de gestão de políticas públicas de forma mais eficaz. A criação de redes e fóruns temáticos passa a ser um formato de organização, os quais se espalham pelo Brasil afora. Estudo realizado por Scherer-Warren (2006) identifica três níveis de organização da sociedade civil brasileira para o "encaminhamento das ações em prol de políticas sociais e públicas, protestos sociais, manifestações simbólicas e pressões políticas”, os quais ela denomina de 'associativismo local', 'articulações interorganizacionais' e 'mobilizações na esfera pública' (SCHERER-WARREN, 2006, p. 110). O segundo e o 
terceiro nível vão ganhar força a partir dos anos de 1990, quando novas demandas são colocadas para os movimentos sociais, exigindo novas formas de organização e atuação.

Destaca-se nesse campo de ação política a participação nas experiências de orçamento participativo que iniciaram na segunda metade dos anos de 1980, tendo a primeira iniciativa realizada no município de Porto Alegre, no estado do Rio Grande do Sul, em 1989. Desse período em diante, outras experiências vão ser iniciadas em outros municípios brasileiros ao longo dessa década (HOROCHOVSKI; CLEMENTE, 2012). Inicialmente nas prefeituras administradas pelo Partido dos Trabalhadores, mas, logo em seguida, começam a se ampliar para além das prefeituras dirigidas por este partido. Outras agremiações partidárias de orientação progressista começam também a desenvolver formatos de participação cidadã na elaboração do orçamento público local, denominando-os também de "Orçamento Participativo", apesar da diversidade de desenhos organizativos e metodológicos para sua implementação (HELENA; LÜCHMANN, 2014).

Tendo em vista as limitações de iniciativas por parte do poder executivo local para a realização de orçamentos participativos, organizações da sociedade civil começam a se mobilizar e reivindicar dos prefeitos a participação cidadã no planejamento dos municípios, através da participação popular no processo de elaboração do orçamento público, principal instrumento de planejamento do município para a realização de políticas públicas. Mesmo sem a iniciativa do poder executivo e sob sua resistência, organizações e movimentos sociais começam a incidir na elaboração do orçamento, através da criação de comissões e fóruns de cidadãos que pressionam os representantes dos poderes executivo e legislativo a cumprir as normas legais previstas para o planejamento urbano, assim como para a elaboração e aprovação do orçamento público pelos poderes constituídos, atividade que se realiza, na maioria dos municípios brasileiros, dentro de gabinetes com a participação dos secretários e burocratas. Após sua elaboração são aprovados pelo poder legislativo sem o cumprimento das normas previstas na legislação, impedindo assim o processo de transparência dos recursos públicos. 
No Brasil, nos últimos anos, diversas experiências que rompem com essa prática política por parte dos representantes do poder público vão se realizar, tendo a participação de organizações da sociedade civil, e sendo a proposição no processo de elaboração do orçamento e controle social seu principal foco. Destaco aqui a experiência desenvolvida no Rio de Janeiro através do Fórum Popular de Orçamento criado em 06 de dezembro de 1995 e duas iniciativas que aconteceram na Paraíba: o Fórum de Defesa da Cidadania de Lagoa Seca (BALCÃO; TEIXEIRA, 2003) e o Fórum das Entidades e Movimentos Sociais de Guarabira (MOREIRA, 2008).

O estudo realizado por Balcão e Teixeira sobre a experiência do Rio de Janeiro nos ajuda a pensar sobre as demais iniciativas que acontecem em outros municípios brasileiros, ao fazer a seguinte afirmação:

\footnotetext{
Constata-se que a organização e a dinâmica implementada pelo Fórum possibilitaram a constituição de um embrião de esfera pública, ampliando o espaço de controle social sobre o orçamento público. O Fórum é um novo ator social, que possibilita alterar a agenda de prioridades em disputa na cena política do Rio de janeiro, na perspectiva do enfrentamento das desigualdades e do fortalecimento da dinâmica democrática (BALCÃO; TEIXEIRA, 2003).
}

Essa realidade que vai emergir nos municípios paraibanos onde ocorrem iniciativas semelhantes. No município de Guarabira o processo de organização se deu com a organização do Fórum das Entidades e Movimentos Sociais fundado em 1995, com a colaboração do Serviço de Educação Popular (SEDUP), organização não governamental sediada no mesmo município. No município de Lagoa Seca foi criado o Fórum em Defesa da Cidadania, em 1988, formado por entidades e movimentos sociais, com a colaboração do Centro de Ação Cultural (CENTRAC). É importante destacar que tais experiências se realizaram em municípios em que não tinha sido instituído o Orçamento Participativo, a ação política partiu dos atores da sociedade civil.

Assinala-se, portanto, que a participação das organizações e movimentos sociais nos espaços públicos traz à tona novas demandas para sua atuação na sociedade, passando a exigir novas habilidades e capacidades na relação com o Estado. Nesse sentido afirma Moreira (2008, p. 142): “A participação cidadã nos espaços públicos tem se apresentado como prática 
fundamental para a ampliação dos processos de democratização do poder local e controle de suas ações no campo das políticas públicas”.

É importante destacar que os espaços públicos que foram implementados nesse período, tendo como característica o compartilhamento da participação entre atores da sociedade civil e do governo, apresentam limites, tendo em vista que o poder local não favorece a participação da sociedade civil de forma efetiva nos espaços decisórios. A falta de vontade política dos governos locais assim como a frágil organização da sociedade civil são elementos desafiadores nesse novo contexto.

Passado esse primeiro momento, com grande investimento por parte das organizações e movimentos sociais para participarem de tais espaços e incidirem nas políticas públicas, percebe-se que o Estado brasileiro, apesar das mudanças acontecidas após o fim da ditadura militar, dando lugar à construção de processos democráticos, continua com sua forte marca clientelista e autoritária, com pouca permeabilidade para a participação popular nas decisões que tem uma dimensão pública.

O Estado brasileiro, em especial na esfera local, não tem construído as condições para fortalecer a dimensão pública, continua favorecendo uma cultura política tradicional em que as relações políticas são marcadas pelo personalismo e a falta de transparência nas ações públicas. O não fortalecimento de uma ação republicana tem levado à continuidade da indistinção entre o público e o privado. Estudo realizado por grupo de pesquisas da UNICAMP aponta nessa direção.

\footnotetext{
A indistinção entre o público e privado, subjacente a uma concepção oligárquica da política, onde os interesses privados assumem prevalência sobre o interesse público, está no centro de uma matriz básica que continua presidindo a configuração da sociedade brasileira, e em relação a qual as instituições políticas da democracia representativa liberal se acomodaram sem rupturas significativas (GRUPO DE ESTUDO SOBRE CONSTRUÇÃO DEMOCRÁTICA, 1998/99, p. 45-46).
}

Esta situação política presente em nossos municípios, como demostra o estudo, tem dificultado a efetividade de uma cultura democrática. O processo de democratização em curso no Brasil tem sido construído com muitos desafios e limites. Os movimentos e organizações sociais têm dado uma contribuição relevante, ao se colocar como ator político importante nos 
cenário político contemporâneo, desenvolvendo ações no sentido de democratizar os espaços decisórios do Estado, de forma a ganhar cada vez mais transparência.

Nos últimos anos, com a aprovação de novas leis que fortalecem a perspectiva da democratização do Estado, a exemplo da Lei de acesso à informação (BRASIL, 20011) e à lei de combate à corrupção, as inciativas por parte dos movimentos sociais e da sociedade civil têm se intensificado. A sociedade brasileira tem cada vez mais ficado atenta aos fatos e atos governamentais que não favorecem a participação cidadã na coisa pública.

Realidade que tem se refletido no campo das políticas públicas, com a participação efetiva dos movimentos sociais nos espaços públicos que foram se constituindo ao longo desse período de democratização da sociedade. Mesmo tendo claro os limites e desafios enfrentados, não podemos desconhecer os avanços em termos de processo participativo no campo da proposição e controle social das políticas públicas. A presença das organizações e movimentos sociais nas diversas conferências nos âmbitos local, estadual e nacional, a participação nos processos de elaboração dos orçamentos públicos, o envolvimento nas comissões e fóruns de discussão e deliberação de políticas sociais fazem parte desse processo. Trata-se de experiências que têm conseguido questionar e problematizar a cultura política hegemônica na sociedade brasileira e apontado para outras formas de se fazer política que não se restringem aos mecanismos da democracia representativa; ampliam-se os horizontes políticos para formatos de participação que se direcionam para a democracia participava.

\section{CONSIDERAÇÕES FINAIS: LIMITES E POSSIBILIDADES}

Consideramos que a presença das organizações e movimentos sociais teve e tem um papel importante nos processos de democratização da sociedade, destacando-se como atores coletivos relevantes para as mudanças políticas contemporâneas acontecidas no Brasil. As conquistas sociais e políticas na Constituição de 1988 são resultados dessa participação cidadã ativa.

A multiplicação dos espaços participativos ocorridos nos últimos tempos, a exemplo dos conselhos gestores de políticas, conferências, orçamentos participativos etc. evidencia 
essa realidade, mesmo diante das continuidades e resistências. Como afirmam Almeida e Tatagiba (2012, p. 70), “o projeto participativo se impôs como princípio na sociedade”. A falta de vontade política por parte dos governos aparece como um limite para a consolidação e eficiência desse projeto participativo, embora em qualquer município, independente do partido que esteja no poder, ignore essa realidade política. Quando o governo não toma a iniciativa de criar tais espaços, as organizações e movimentos sociais pressionam para a sua efetivação, ou é forçado a cumprir a legislação, pois o não cumprimento leva à suspensão de recursos para o município.

A eficácia e eficiência dos espaços participativos, muitas vezes, não acontecem a contento, tendo em vista os objetivos que inspiraram sua criação. Sua efetividade tem a ver com a vontade política dos governos, mas também com a capacidade das organizações da sociedade civil na dinâmica desses espaços.

Trata-se de um movimento de renovação da cultura política, seja por parte dos representantes do poder executivo quanto do poder legislativo, ambos com seus representantes com uma mentalidade política que tem como referência apenas a democracia representativa, e pouco tem feito para a efetivação da democracia participativa como assegura a Constituição de 1988; ao contrário, tem dificultado a ação da sociedade civil nessa direção. As mudanças que vêm ocorrendo na gestão local, na perspectiva da democratização e ampliação da participação cidadã, têm uma contribuição relevante dos atores coletivos da sociedade civil, em especial dos movimentos sociais, os quais participam ativamente dos espaços e mecanismos que reforçam a democracia participativa. 


\section{REFERÊNCIAS}

ALMEIDA, Carla; TATAGIBA, Luciana. Os conselhos gestores sob o crivo da política: balanços e perspectivas. Serviço Social e Sociedade, São Paulo, n. 109, p. 68-92, jan./mar. 2012.

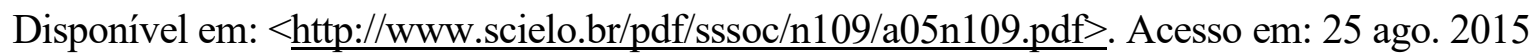

BALCÃO, Neide; TEIXEIRA, Ana Claúdia C. (Org.). Controle social do orçamento público. São Paulo: Instituto Polis, 2003.

BRASIL. Constituição. Brasília: Câmara dos deputados/Coordenação de publicações, 2002.

. Lei no 12.527. Brasília: Presidência da República/Casa Civil, nov. 2011. Disponível em: $<$ http://www.planalto.gov.br/ccivil_03/ ato 2011-2014/2011/lei/112527.htm>. Acesso em: 25 ago. 2015.

. Lei n⿳0 12.846. Brasília: Presidência da República/Casa Civil, ago. 2013. Disponível em: <http://www.planalto.gov.br/ccivil 03/ ato2011-2014/2013/lei/112846.htm>. Acesso em 25 ago. 2015.

GRUPO DE ESTUDO SOBRE A CONSTRUÇÃO DEMOCRÁTICA. Os movimentos sociais e a construção democrática: sociedade civil, esfera pública e gestão participativa. Ideias, Campinas: Instituto de Filosofia e Ciências Humanas da UNICAMP, ano 06, n. 2, 1999.

. Os movimentos sociais e a construção democrática: sociedade civil, esfera pública e gestão participativa. Ideias, Campinas: Instituto de Filosofia e Ciências Humanas da UNICAMP, ano 6, n. 1, 1998.

HELENA Lígia; LÜCHMANN, Hahn. 25 anos de Orçamento Participativo: algumas reflexões analíticas. Política \& Sociedade, v. 13, n. 28, set./dez. 2014. Disponível em: $<$ http://dx.doi.org/10.5007/2175-7984.2014v13n28p167>. Acesso em: 25 ago. 2015.

HOROCHOVSKI, Rodrigo Rossi; CLEMENTE, Augusto Junior. Democracia deliberativa e orçamento público: experiências de participação em Porto Alegre, Belo Horizonte, Recife e Curitiba. Sociologia e Política, Curitiba, v. 20, n. 43, 2012. Disponível em: $<$ http://www.scielo.br/pdf/rsocp/v20n43/a07v20n43.pdf $>$. Acesso em: 28 ago. 2015. 
KRISCHKE, Paulo; MAINWARING, Scott. A igreja nas bases em tempo de transição (19741985). Porto Alegre: L\&PM; CEDC, 1986.

MICHILES, Carlos et al. Cidadão constituinte: a saga das emendas populares. Rio de Janeiro: Paz e Terra, 1989.

MOREIRA, Orlandil de Lima. Gestão pública local e participação social nos conselhos municipais da região do brejo da Paraíba: mudanças e continuidades. Tese (doutorado) PUC/SP Programa da pós-graduação em Ciências Sociais, São Paulo, 2002.

. Educação popular na trilha da participação cidadã. In: NASCIMENTO, Aristonildo Chagas Araújo; MOURÃO, Arminda Rachel Botelho (Org.). Educação, culturas e diversidades. Manaus: Edua, 2011. v. 1.

. ONGs, movimentos sociais e educação popular: uma reflexão sobre a experiência educativa do SEDUP. In: JESINE, Edineide et al. (Org.). Educação popular e movimentos sociais: dimensões educativas na sociedade globalizada. João Pessoa: Ed. da UFPB, 2008.

SADER, Eder. Quando novos personagens entraram em cena: experiências e lutas dos trabalhadores da grande São Paulo - 1970-1980. Rio de Janeiro: Paz e Terra, 1988.

SANTOMÉ, Jurjo Torres. Currículo escolar e justiça social: o cavalo de Troia da educação. Porto Alegre: Penso, 2013.

SCHERER-WARREN, I. Das mobilizações às redes de movimentos sociais. Sociedade e Estado, Brasília, v. 21, n. 1, p. 109-130, jan./abr. 2006. Disponível em:

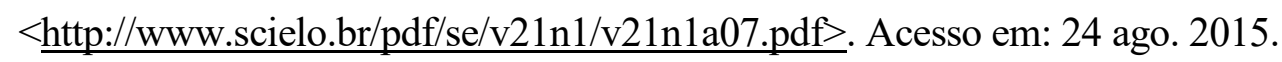

